\title{
Proton conductance at elevated temperature: formulation and investigation of poly(4-styrenesulfonic acid)/4-aminobenzylamine/phosphoric acid membranes
}

\author{
Jalal Jalili and Vincenzo Tricoli* \\ Department of Civil and Industrial Engineering, University of Pisa, Pisa, Italy
}

\section{Edited by:}

Maria Luisa Di Vona, University of

Rome Tor Vergata, Italy

\section{Reviewed by:}

Mathieu Marrony, European Institute for Energy Research, Germany

Enrico Negro, University of Padova, Italy

Anna Donnadio, University of Perugia, Italy

\section{*Correspondence}

Vincenzo Tricoli, Department of Civil and Industrial Engineering, University of Pisa, Largo L. Lazzarino, Pisa 56122, Italy

e-mail:v.tricoli@diccism.unipi.it
4-Aminobenzylamine (ABA) and phosphoric acid (PA) were blended in various proportions with poly(4-styrenesulfonic acid) (PSSA) to form a new group of membranes exhibiting proton conductance under water-free conditions. The 4-ABA molecule, possessing an aniline-like and benzylamine-like functional group, can interact both with the PA and the PSSA via nucleophilic interaction, thereby allowing proton jumping in the structure. Physico-chemical and thermal characteristics of the prepared solid membranes were investigated by IR spectroscopy and thermogravimetric analysis, respectively. Electrochemical impedance spectroscopy was employed to investigate their proton-conductance properties. Transparent composite membranes were prepared. However, the membranes are opaque for relatively high content of PA. These membranes are thermally stable up to $300^{\circ} \mathrm{C}$. The proton conductivity increases with temperature and also with content of PA. Values as high as $1.8 \times 10^{-3} \mathrm{~S} \mathrm{~cm}^{-1}$ were measured at $190^{\circ} \mathrm{C}$ in fully anhydrous condition.

Keywords: medium-temperature fuel cell, proton conduction, water-free, membranes, polymer

\section{INTRODUCTION}

The polymer electrolyte membrane fuel cell (PEMFC) has attracted global attention as clean power source for portable electronic devices, transportation systems, and power generating apparatuses. There are, however, some issues to be overcome before the PEMFC technology becomes commercially viable. Improvement of current platinum-based cathode catalysts for the oxygen reaction is one issue. Another issue is poisoning of the anode catalyst due to the $\mathrm{CO}$ either present in fuel feed or produced by the electro-oxidation reaction of fuel (Jiang et al., 2006; Zhang et al., 2006; Cheng et al., 2007; Cui et al., 2009). These problems can be significantly mitigated by operation at elevated temperature $\left(100-200^{\circ} \mathrm{C}\right)$. However, that requires development of new durable membranes enabling operation at high temperatures and, consequently, water-free conditions (Zhang et al., 2006). It should be pointed out that operation at elevated temperature has two more beneficial effects: first, it improves heat removal from the fuel cell and possibly enables heat recovery from gas out-streams; second, it facilitates overcoming water-related issues, namely flooding of the electrodes pores by the liquid water, thereby reducing the complexity and cost of the system (Oetjen et al., 1996). PA fuel cells were conceived to operate at such elevated temperatures. Here, the electrolyte is $\mathrm{PA}$ impregnated into a porous $\mathrm{SiC}$ matrix. However, two important issues are that the PA electrolyte is a liquid above $42^{\circ} \mathrm{C}$ and, moreover, it is somewhat volatile at the elevated operation temperatures of the fuel cell (Larminie and Dicks, 2000). These issues can be overcome by employing a solid polymer electrolyte membrane. However, the ability of such a membrane to transfer protons from anode to cathode relies on water presence critically. Conductivity of these membranes dramatically drops above $100^{\circ} \mathrm{C}$ due to loss of water. Therefore, in order to still benefit from advantages connected to elevated-temperature operation, development of new, water-free polymer electrolyte materials, and also new concepts to make membranes thereof (De Martino et al., 2009) is of great importance.

Poly(benzimidazole) (PBI) impregnated in various proportions with PA was proposed as a proton-conducting membrane material able to operate at elevated temperature and low humidity (Wainright et al., 1995). Another promising approach investigated extensively is to incorporate non-volatile, amphoteric fillers able to interact with protons much like water. These fillers can assist protons to hop from site to site (Grotthuss mechanism) through a dynamic hydrogen-bonded networks (Parvole and Jannasch, 2008; Tricoli et al., 2012). In this regard, heterocyclic compounds such as imidazole, benzimidazole, pyrazole, and triazole have been incorporated into various polymeric matrices (Bozkurt et al., 2003; Sevil and Bozkurt, 2004; Yamada and Honma, 2005; Goktepe et al., 2008). Poly(acrylic acid), poly(4styrenesulfonic acid) (PSSA) and poly(vinylphosphonic acid) are examples of such matrices. The best proton conductivities achieved were about $1 \times 10^{-3} \mathrm{~S} \mathrm{~cm}^{-1}$ at $150^{\circ} \mathrm{C}$ under anhydrous condition (Yamada and Honma, 2005). Although extensive works have been performed, issues regarding modest proton conductivity, leakage of the filler, and scarce mechanical properties of composite membranes still remain. In this work, we incorporated 4aminobenzylamine (ABA) (Figure 1A) and PA into PSSA in various proportions. ABA can bind both to the PA and the PSSA matrix by nucleophilic interaction of its amine groups (Figure 1B). IR spectroscopy was used to asses such interactions. Thermal stability of the prepared membranes was evaluated by thermogravimetric 


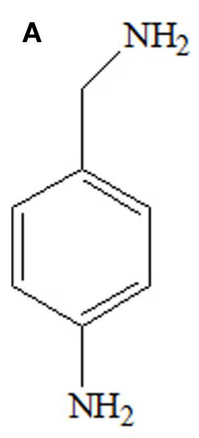<smiles>CC(C)(C)C(C(=O)O)c1ccc(S(=O)(=O)[O-])cc1</smiles><smiles>[NH3+]Cc1ccc([NH3+])cc1</smiles><smiles>O=P([O-])(O)O</smiles>

FIGURE 1 | Chemical structures of (A) ABA molecule and (B) PSSA/ABA/PA composite membrane.

analysis (TGA). Proton conductivity for different molar ratios of PSSA/ABA/PA was investigated by electrochemical impedance spectroscopy (EIS).

\section{MATERIALS AND METHODS MATERIALS AND MEMBRANES PREPARATION}

Poly(4-styrenesulfonic acid) (18 wt $\%$ solution in water, $M_{\mathrm{w}}=75,000$ ), ABA (purity 99\%), and PA (anhydrous, purity 99\%) were purchased from Aldrich and used as received. PSSA/ABA/PA blends with molar ratios of 1:1:0, 1:0.5:0.5, 1:1:1, and 1:1:2 were prepared. Briefly, a measured amount of ABA was dissolved in $2 \mathrm{ml}$ of the PSSA solution at room temperature and then the appropriate quantity of the PA water-solution was added under stirring for $1 \mathrm{~h}$. The resulting solution was poured into a Teflon dish and transferred to a convection oven at $45^{\circ} \mathrm{C}$ to completely evaporate water. The obtained films had thickness of $400-500 \mu \mathrm{m}$ and diameter of $2.3 \mathrm{~cm}$. Then $6-\mathrm{mm}$ disks were cut and utilized for the conductivity measurements. The composite membranes with molar ratios of 1:1:0 and 1:0.5:0.5 were transparent; however, composites of $1: 1: 1$ and $1: 1: 2$ molar ratios were fairly opaque. For brevity, PSSA/ABA/PA blends with molar ratios of 1:1:0, 1:0.5:0.5, 1:1:1, and 1:1:2 are addressed by $S 1, \mathrm{~S} 2$, S3, and S4, respectively, in the following account. Prior to further experiments, the cast membranes were stored in a silica-gel desiccator.

\section{IR SPECTROSCOPY}

The IR spectra of the composite membranes were recorded in the $600-4000 \mathrm{~cm}^{-1}$ range on a Bruker (mod. Tensor 27) FT-IR spectrometer with attenuated total reflectance (ATR) technique. The IR spectra of bare PSSA and ABA are also presented for comparison.

\section{THERMOGRAVIMETRIC ANALYSIS}

Thermogravimetric analysis (TGA) was performed by a TA instrument (mod. TGA Q-500) under nitrogen from 50 to $500^{\circ} \mathrm{C}$ with heating rate of $10^{\circ} \mathrm{C} \mathrm{min}^{-1}$.

\section{PROTON CONDUCTION}

The proton conductivity of casted membranes was investigated by EIS, using a Solartron 1255/1287 frequency response analyzer/electrochemical workstation interface equipped with $\mathrm{Z}$-view software for spectra analysis. EIS spectra were recorded in the frequency range of $10^{-1}-10^{6} \mathrm{~Hz}$ with applied-voltage amplitude of $10 \mathrm{mV}$. The test cell has a sandwich structure with the membrane clamped between two stainless-steel disk electrodes. Once locked, the electrodes/membranes assembly was automatically sealed by a system of Viton O-rings, thereby remaining isolated from the environment. Full details about the cell can be found elsewhere (Hu et al., 2008). The measurements were performed in the temperature range of $30-190^{\circ} \mathrm{C}$ under fully anhydrous condition. The membrane was lodged in the open test cell and then transferred to a vacuum oven $\left(10^{-2}\right.$ torr $)$ at $100^{\circ} \mathrm{C}$, where it was first let dehydrate for at least $12 \mathrm{~h}$ and then sealed by locking the cell while it was in the oven.

\section{RESULTS AND DISCUSSION THERMAL ANALYSIS}

We recorded the TGA traces for three samples: (1) the bare PSSA; (2) the two-components (PSSA and ABA) sample, i.e., S1 and (3), a sample where all three components (PSSA, ABA, and PA) are present, S3. The TGA plots are shown in Figure 2. The trace of bare PSSA is also shown for reference. The TG trace of PSSA displays a weight loss of $\approx 20 \%$ up to $220^{\circ} \mathrm{C}$ due to absorbed water release (Yang, 2011). Then, two main losses are observable: the first one in the range of $280-400^{\circ} \mathrm{C}$, is assigned to desulfonation of the aromatic ring, while the second one from 400 to $450^{\circ} \mathrm{C}$, to main-chain cleavage (Yang, 2011).

For TGA of S1, the first weight loss of ca. $2 \%$ from 90 to $320^{\circ} \mathrm{C}$ is attributed to release of physically bound water (i.e., water moisture inevitably absorbed from the environment before or during any experimental step). The second and third convoluted weight losses from 320 to $450^{\circ} \mathrm{C}$ are attributable to desulfonation and cleavage of polymer backbone, respectively, although release of ABA cannot be ruled out, despite its very high boiling point $\left(349^{\circ} \mathrm{C}\right)$ and nucleophilic bond to the sulfonic groups of PSSA. Comparing the TG traces of bare PSSA and S1, it can be inferred that presence of ABA makes the desulfonation temperature of PSSA higher by c.a. $40^{\circ} \mathrm{C}$, probably due to the interactions between the benzylamine group of ABA and the sulfonic group of PSSA. Existence of this interaction is also supported by the fact that the amount of absorbed water is much less in S1 than that in bare PSSA as evidenced by the TG traces. In fact, binding of the benzylamine groups of ABA to the sulfonic acid groups of PSSA is expected to depress the amount of absorbed moisture from the environment. The TGA trace of S3 displays an initial weight loss of 5\% up to $300^{\circ} \mathrm{C}$ ascribable to release of absorbed moisture and also to the water release from the condensation reaction of $\mathrm{P}-\mathrm{OH}$ groups in PA (Lee et al., 2012). From 310 to $360^{\circ} \mathrm{C}$, desulfonation of aromatic rings of PSSA occurs, while main polymer chain undergoes 


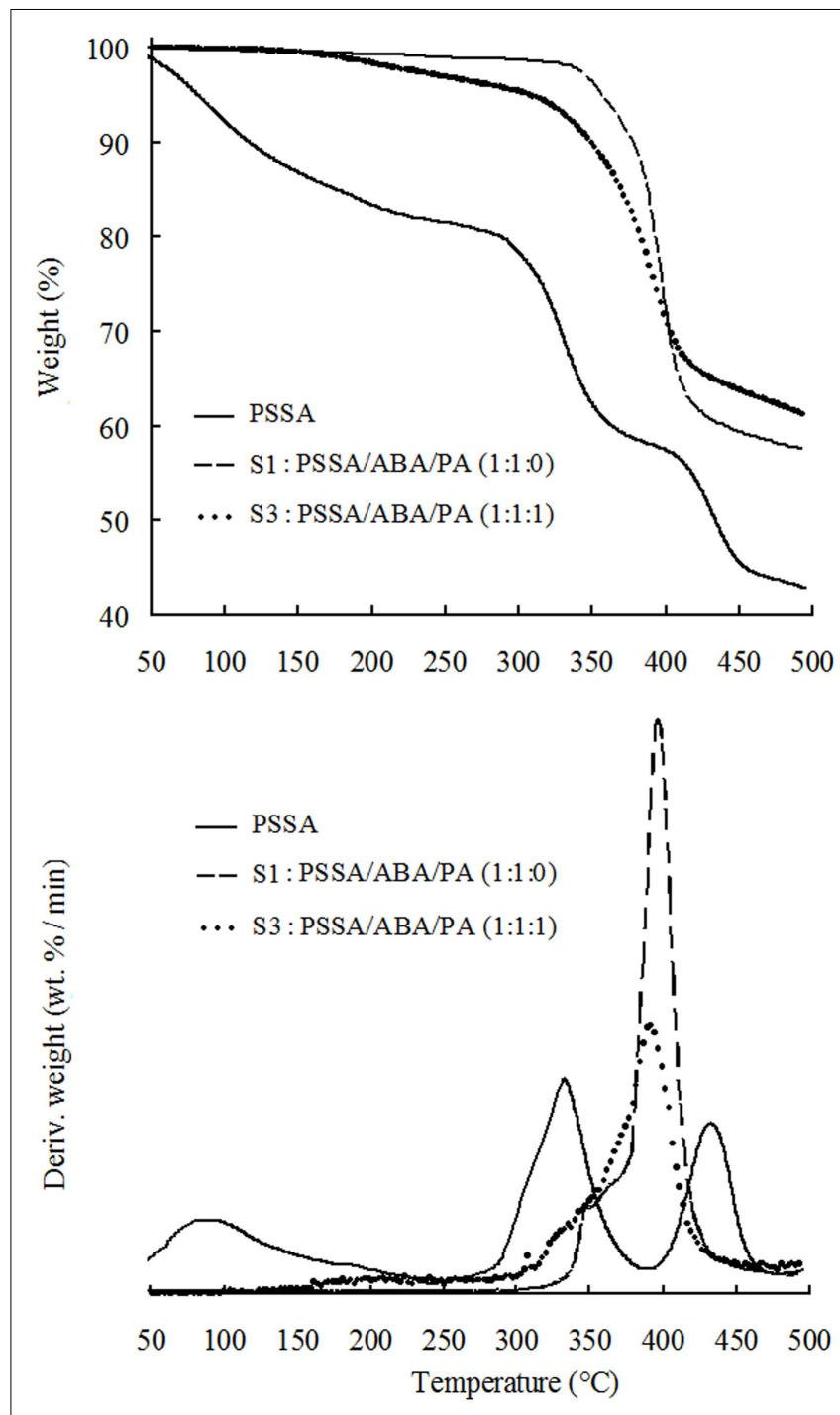

FIGURE 2 |TGA traces of PSSA, S1: PSSA/ABA/PA (1:1:0) and S3: PSSA/ABA/PA (1:1:1) composite membranes.

cleavage from 360 to $450^{\circ} \mathrm{C}$. Again, release of ABA is also possible in those temperature ranges. In summary, TGA results show that PSSA/ABA/PA membranes are thermally stable up to $300^{\circ} \mathrm{C}$ as a result of the acid-base interactions of the PSSA matrix with ABA.

\section{IR SPECTROSCOPY}

In Figure 3, IR spectra of PSSA, ABA, S1, and S3 are presented. The peak at $1650 \mathrm{~cm}^{-1}$ corresponds to water bound to the sulfonic groups of PSSA. Apparently, the intensity for S1 is considerably attenuated as compared to the bare PSSA sample, implying a decreased amount of absorbed water in agreement with the above TGA results. It is also worthwhile to mention the new peak at c.a. $1170 \mathrm{~cm}^{1}$ in the $\mathrm{S} 1$ spectrum. This peak is assignable to the $\mathrm{SO}_{3}{ }^{-}$groups (Rajagopalan et al., 1987) and is interpretable as the result of the protons of $\mathrm{SO}_{3} \mathrm{H}$ groups transferred to the nitrogen atom of benzylamine moiety of ABA. That creates ionized $\mathrm{SO}_{3}{ }^{-}$groups, which gives rise to this new

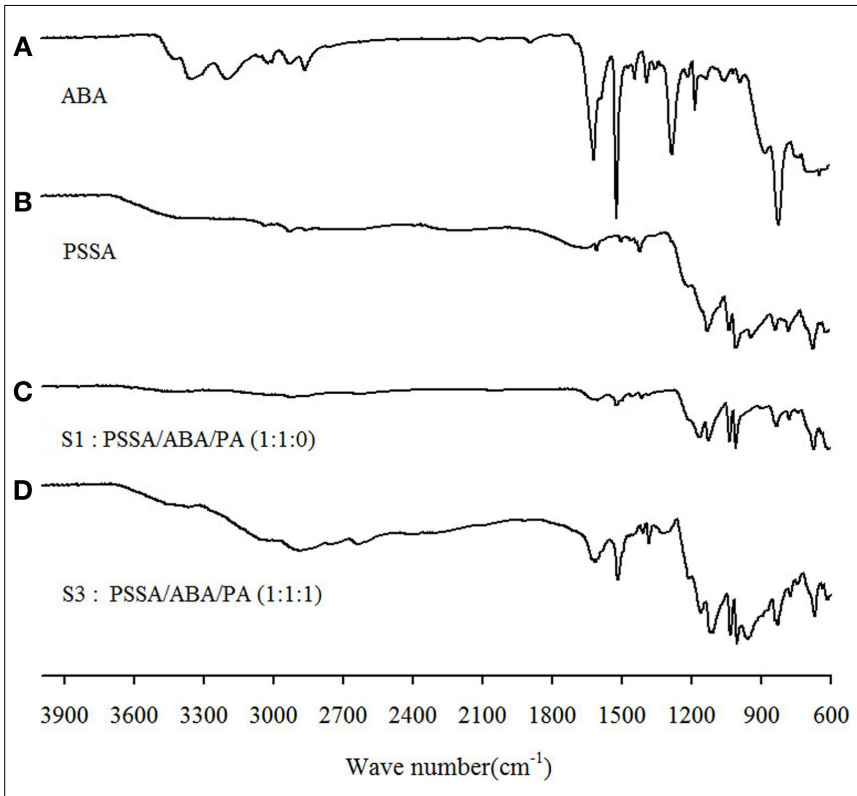

FIGURE 3 | FT-IR spectra of (A) ABA, (B) PSSA, (C) S1: PSSA/ABA/PA (1:1:0), and (D) S3: PSSA/ABA/PA (1:1:1) composite membranes.

Table 1 | FT-IR assignments of PSSA.

\begin{tabular}{ll} 
Wave no. $\left(\mathbf{c m}^{-\mathbf{1}}\right)$ & Assignment \\
\hline $1037-1170$ & $\begin{array}{l}\mathrm{SO}_{3}{ }^{-} \text {symmetric and asymmetric stretching } \\
\text { (Rajagopalan et al., 1987; Glipa et al., 1999) }\end{array}$ \\
1226 & $\begin{array}{l}\mathrm{SO}_{3} \mathrm{H} \text { symmetric stretching (Rajagopalan et al., 1987; } \\
\text { Glipa et al., 1999) }\end{array}$ \\
1650 & $\mathrm{O}-\mathrm{H}$ bending of $\mathrm{H}_{2} \mathrm{O}_{\text {abs }}($ Tsai et al., 2011) \\
$3000-3670$ & $\mathrm{O}-\mathrm{H}$ stretching of $\mathrm{H}_{2} \mathrm{O}_{\text {abs }}$ (Tsai et al., 2011)
\end{tabular}

peak. Finally, in the spectrum of S3, new peaks appear at 945 and $1861-2750 \mathrm{~cm}^{-1}$. Such peaks are ascribable to symmetric and asymmetric stretching vibration of $\mathrm{O}-\mathrm{P}-\mathrm{O}$ groups and $\mathrm{OH}-$ stretching of $\mathrm{P}-\mathrm{OH}$ groups in $\mathrm{H}_{2} \mathrm{PO}_{4}{ }^{-}$(Glipa et al., 1999). A summary of the PSSA IR-peaks assignment, based on past studies, is provided in Table $\mathbf{1}$ and served as the reference for the above analysis.

\section{PROTON CONDUCTIVITY}

A typical Nyquist plot of our samples at different temperatures is shown in Figure 4. All impedance responses were fitted with the equivalent circuit model shown in figure inset. The semi-circle at high frequencies is representative of the neat impedance of the bulk membrane and modeled by the parallel of a resistor $R$ with a constant phase element, CPE. $R$ is the actual ohmic resistance of the membrane, whereas the CPE accounts for capacitive behavior of the membrane. The tail at low frequencies of the Nyquist plot represents the impedance of the membrane/electrodes interfaces and is modeled by $\mathrm{CPE}_{\text {int }}$, which is in series with the neat impedance of the bulk membrane. The proton conductivity was 


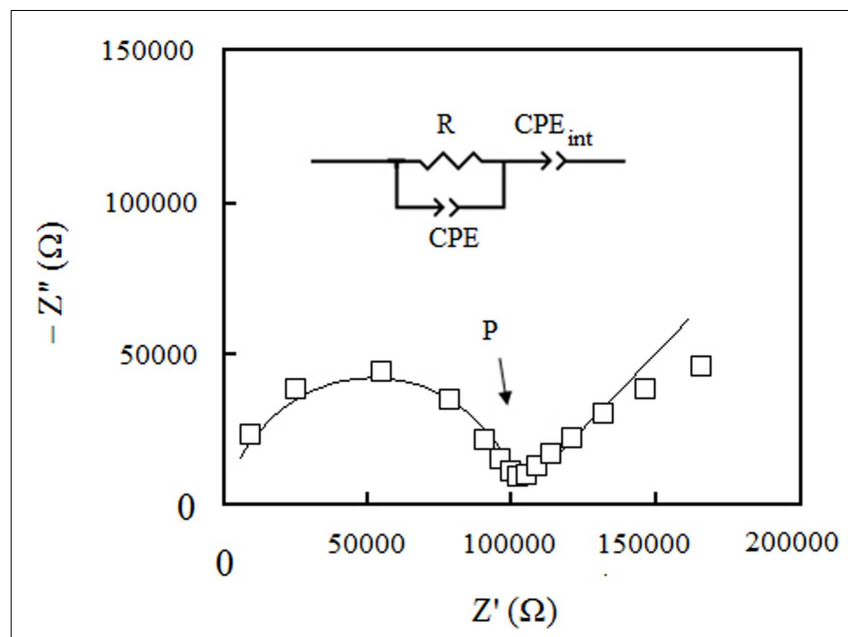

FIGURE 4 | Nyquist plot of S1: PSSA/ABA/PA (1:1:0) membrane under fully anhydrous conditions at $150^{\circ} \mathrm{C}$

calculated from $R$ as extracted from the fits. This resistance can be determined also from the real part of the impedance where the semi-circle portion in Nyquist plot links to the tail-like portion (point $\mathrm{P}$ in figure).

Figure 5 displays the proton conductivity behavior vs. temperature in fully anhydrous condition for all the composite membranes. Apparently, Arrhenius-type behavior is observed with activation energies about $90 \mathrm{~kJ} \mathrm{~mol}^{1}$ for all samples. For S1, which does not contain PA, the proton conductivity reaches $4 \times 10^{-5} \mathrm{~S} \mathrm{~cm}^{-1}$ at $190^{\circ} \mathrm{C}$. For the PA-containing samples S2, S3, and S4, conductivity value is higher and increases with PA content. The highest value of $1.8 \times 10^{-3} \mathrm{~S} \mathrm{~cm}^{-1}$ was registered at $190^{\circ} \mathrm{C}$ for $\mathrm{S} 4$. Table 2 summarizes the conductivity values at $190^{\circ} \mathrm{C}$ along with the activation energies. From these results, it can be concluded that addition of PA improves proton transport in membranes. In the absence of PA, like in S1, the aniline- and benzylamine groups act as proton-hopping sites to conduct protons. In this case, the protons come solely from the sulfonic groups of PSSA. For the S2, S3, and S4 composites, an additional amount of protons comes also from the PA present; thus, the observed increase of conductivity should not come as a surprise. It is important, however, to point out that the presence of $\mathrm{H}_{3} \mathrm{PO}_{4}$ also brings about additional proton-hopping sites within the matrix, namely the $\mathrm{H}_{2} \mathrm{PO}_{4}{ }^{-}$ions created from protonation of aniline groups of ABA by PA. In fact, the $\mathrm{H}_{2} \mathrm{PO}_{4}{ }^{-}$ions are proton-accepting sites and, as such, enable proton jumping. In the end, the observed increase of conductivity consequent to addition of PA is due to both the larger number of protons and proton-hopping sites present.

It is useful to compare the above conductivity values with those of PA-doped PBI membranes. Other authors (Schechter and Savinell, 2002) reported a conductivity of c.a. $9 \times 10^{-3} \mathrm{~S} \mathrm{~cm}^{-1}$ at $200^{\circ} \mathrm{C}$ for a $6: 1 \mathrm{PA} / \mathrm{PBI}$ molar ratio. This conductivity value is five times higher as compared to our S4 membranes. However, it should be pointed out that the PA content was also sensibly higher: about $68 \mathrm{wt} \%$ in $6: 1 \mathrm{PA} / \mathrm{PBI}$ membranes vs. ca. $38 \%$ in $\mathrm{S} 4$.

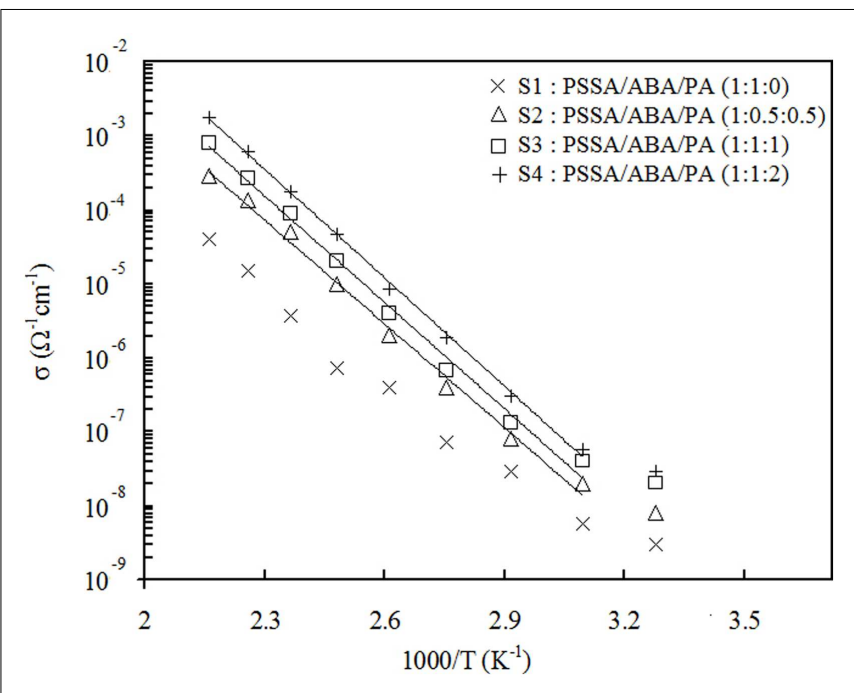

FIGURE 5 | Temperature dependence of conductivity in PSSA/ABA/PA composite membranes under fully anhydrous condition.

Table 2 | Proton conductivity and activation energy.

\begin{tabular}{|c|c|c|}
\hline Sample & $\begin{array}{l}\text { Conductivity at } \\
190^{\circ} \mathrm{C}\left(\mathrm{S} \mathrm{cm}^{-1}\right)\end{array}$ & 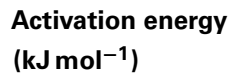 \\
\hline S1 & $\approx 4 \times 10^{-5}$ & $\approx 90$ \\
\hline S2 & $2.9 \times 10^{-4}$ & $\approx 90$ \\
\hline S3 & $8.1 \times 10^{-4}$ & $\approx 90$ \\
\hline S4 & $1.8 \times 10^{-3}$ & $\approx 90$ \\
\hline
\end{tabular}

\section{CONCLUSION}

We have obtained hybrid membranes made out of a poly(styrenesulfonic acid) (PSSA) matrix incorporating 4-ABA and PA. The basic idea was to accomplish water-free protonconducting membranes where the nucleophilic nitrogen moieties of ABA can work as proton-solvent groups that are able to transfer the proton even in the absence of water. The composites display fairly high thermal stability up to $300^{\circ} \mathrm{C}$. That reasonably appears to be a consequence of the acid-base interactions of PSSA and PA with $\mathrm{ABA}$, which depresses the volatility of both PA and ABA. The PSSA/ABA/PA composite electrolyte with 1:1:2 molar proportion exhibits proton conductivity of $1.8 \times 10^{-3} \mathrm{~S} \mathrm{~cm}^{-1}$ at $190^{\circ} \mathrm{C}$ under fully anhydrous condition. Proton conductivity depends on temperature according to the Arrhenius law behavior with activation energy about $90 \mathrm{~kJ} \mathrm{~mol}^{-1}$, indicative of proton-hopping mechanism. The conductivity values are somewhat lower than that of $\mathrm{PBI} / \mathrm{PA}$ as reported in previous studies. However, it should be pointed out that the PA content in our materials is sensibly lower than that in those PBI membranes. Most importantly, beyond the compounds used in this study, our approach allows employment of a large variety of materials with proton-solvent characteristics, which enables possible improvement of proton conductivity. Thus, the present work has to be intended as a first step of an ongoing effort aimed at development of new water-free protonconducting membranes. More specifically, future development 
can be envisioned in two directions: one is employing alternative Bronsted-base fillers with higher $\mathrm{pK}_{\mathrm{a}}$ to enhance proton-hopping mobility. On the other side, it should be pointed out that these membranes are soluble in water. As a result, they can be used only in dry condition. Therefore, further work is necessary also in developing matrix and filler components, which cannot be easily leached out in the presence of excess water.

\section{ACKNOWLEDGMENTS}

We are grateful to Dr. Sara Filippi for her help with TGA. This work was funded by the Italian MIUR: PRIN-20077NCPS3_002.

\section{REFERENCES}

Bozkurt, A., Meyer, W. H., and Wegner, G. (2003). PAA/imidazole based proton conducting polymer electrolytes. J. Power Sources 123, 126-131. doi:10.1016/S03787753(03)00560-3

Cheng, X., Shi, Z., Glass, N., Zhang, L., Zhang, J. J., Song, D. T., et al. (2007). A review of PEM hydrogen fuel cell contamination: impacts, mechanisms, and mitigation. J. Power Sources 165, 739-756. doi:10.1016/j.jpowsour.2006.12.012

Cui, X. Z., Guo, L. M., Cui, F. M., He, Q. J., and Shi, J. L. (2009). Electrocatalytic activity and $\mathrm{CO}$ tolerance properties of mesostructured $\mathrm{Pt} / \mathrm{WO} 3$ composite as an anode catalyst for PEMFCs. J. Phys. Chem. C 113, 4134-4138. doi:10.1021/jp8079205

De Martino, F., Vatistas, N., and Tricoli, V. (2009). Concept to design membranes for PEMFC: triple-layer ion-conducting membrane. J. Electrochem. Soc. 156, B59-B65. doi:10.1149/1.3005963

Glipa, X., Bonnet, B., Mula, B., Jones, D. J., and Rozière, J. (1999). Investigation of the conduction properties of phosphoric and sulfuric acid doped polybenzimidazole. J. Mater. Chem. 9, 3045-3049. doi:10.1039/a906060j

Goktepe, F., Bozkurt, A., and Gunday, S. T. (2008). Synthesis and proton conductivity of poly(styrene sulfonic acid)/heterocycle-based membranes. Polym. Int. 57, 133-138. doi:10.1002/pi.2335

Hu, J., Baglio, V., Tricoli, V., Aricò, A. S., and Antonucci, V. (2008). PEO-PPOPEO triblock copolymer/Nafion blend as membrane material for intermediate temperature DMFC. J. Appl. Electrochem. 38, 543-550. doi:10.1007/s10800-0079471-5

Jiang, R. C., Kunz, H. R., and Fenton, J. M. (2006). Influence of temperature and relative humidity on performance and CO tolerance of PEM fuel cells with NafionTeflonZr $\left(\mathrm{HPO}_{4}\right)^{2}$ higher temperature composite membranes. Electrochim. Acta 51, 5596-5605. doi:10.1016/j.electacta.2006.02.033

Larminie, J., and Dicks, A. (2000). Fuel Cell Systems Explained. J. Wiley \& Sons.

Lee, S. I., Yoon, K. H., Song, M., Peng, H., Page, K. A., Soles, C. L., et al. (2012). Structure and properties of polymer electrolyte membranes containing phosphonic acids for anhydrous fuel cells. Chem. Mater. 24, 115-122. doi:10. $1021 / \mathrm{cm} 202064 \mathrm{x}$

Oetjen, H. F., Schmidt, V. M., Stimming, U., and Trila, F. (1996). Performance data of a proton exchange membrane fuel cell using $\mathrm{H} 2 / \mathrm{CO}$ as fuel gas. J. Electrochem. Soc. 143, 3838-3842. doi:10.1149/1.1837305
Parvole, J., and Jannasch, P. (2008). Polysulfones grafted with poly(vinylphosphonic acid) for highly proton conducting fuel cell membranes in the hydrated and nominally dry state. Macromolecules 41, 3893-3903. doi:10.1021/ma800042m

Rajagopalan, R., Eisenberg, M., and Tannenbaum, A. (1987). Ionomeric blends. V. FTIR studies of ionic interactions in polyurethane-styrene blends. J. Polym. Sci. B Polym. Phys. 25, 663-671. doi:10.1002/polb.1987.090250316

Schechter, A., and Savinell, R. F. (2002). Imidazole and 1-methyl imidazole in phosphoric acid doped polybenzimidazole, electrolyte for fuel cells. Solid State Ionics 147, 181-187. doi:10.1016/S0167-2738(02)00040-1

Sevil, F., and Bozkurt, A. (2004). Proton conducting polymer electrolytes on the basis of poly(vinylphosphonic acid) and imidazole. J. Phys. Chem. Solids 65, 1659-1662. doi:10.1016/j.jpcs.2004.04.001

Tricoli, V., Orsini, G., and Anselmi, M. (2012). Ion transport in a class of imidazolebased liquid/solid protic ionics. Phys. Chem. Chem. Phys. 14, 10979-10986. doi: $10.1039 / \mathrm{c} 2 \mathrm{cp} 41027 \mathrm{c}$

Tsai, C. E., Lin, C. W., Rick, J., and Hwang, B. J. (2011). Poly(styrene sulfonic acid)/poly(vinyl alcohol) copolymers with semi-interpenetrating networks as highly sulfonated proton-conducting membranes. J. Power Sources 196, 5470-5477. doi:10.1016/j.jpowsour.2011.01.020

Wainright, J. S., Wang, J.-T., Weng, D., Savinell, R. F., and Litt, M. (1995). Aciddoped polybenzimidazoles: a new polymer electrolyte. J. Electrochem. Soc. 142, L121-L123. doi:10.1149/1.2044337

Yamada, M., and Honma, I. (2005). Anhydrous proton conducting polymer electrolytes based on poly(vinylphosphonic acid)-heterocycle composite material. Polymer 46, 2986-2992. doi:10.1016/j.polymer.2005.02.056

Yang, C. C. (2011). Fabrication and characterization of poly(vinylalcohol)/ montmorillonite/poly(styrenesulfonic acid) proton-conducting composite membranes for direct methanol fuel cells. Int. J. Hydrogen Energy 36, 4419-4431. doi:10.1016/j.ijhydene.2011.01.011

Zhang, J., Xie, Z., Tang, Y., Song, C., Navessin, T., Shi, Z., et al. (2006). High temperature PEM fuel cells. J. Power Sources 160, 872-891. doi:10.1016/j.jpowsour. 2006.05.034

Conflict of Interest Statement: The authors declare that the research was conducted in the absence of any commercial or financial relationships that could be construed as a potential conflict of interest.

Received: 03 May 2014; accepted: 26 June 2014; published online: 14 July 2014. Citation: Jalili $J$ and Tricoli $V$ (2014) Proton conductance at elevated temperature: formulation and investigation of poly(4-styrenesulfonic acid)/4aminobenzylamine/phosphoric acid membranes. Front. Energy Res. 2:28. doi: $10.3389 /$ fenrg. 2014.00028

This article was submitted to Fuel Cells, a section of the journal Frontiers in Energy Research.

Copyright (c) 2014 Jalili and Tricoli. This is an open-access article distributed under the terms of the Creative Commons Attribution License (CC BY). The use, distribution or reproduction in other forums is permitted, provided the original author(s) or licensor are credited and that the original publication in this journal is cited, in accordance with accepted academic practice. No use, distribution or reproduction is permitted which does not comply with these terms. 